\title{
Correction to: An algebraic model for rational naïve-commutative ring $S O(2)$-spectra and equivariant elliptic cohomology
}

\section{David Barnes $^{1}$. J. P. C. Greenlees ${ }^{2}$. Magdalena Kędziorek ${ }^{3}$}

Published online: 4 November 2020

(c) Springer-Verlag GmbH Germany, part of Springer Nature 2020

\section{Correction to: Mathematische Zeitschrift https://doi.org/10.1007/s00209-020-02554-0}

In the original publication, the text "-spectra" was missed out in the terms "G" and "T" at many of the places throughout the article.

The original article has been corrected.

Publisher's Note Springer Nature remains neutral with regard to jurisdictional claims in published maps and institutional affiliations.

The original article can be found online at https://doi.org/10.1007/s00209-020-02554-0.

$凶 \quad$ Magdalena Kędziorek

m.kedziorek@math.ru.nl

David Barnes

d.barnes@qub.ac.uk

J. P. C. Greenlees

john.greenlees@warwick.ac.uk

1 Mathematical Sciences Research Centre, Queen's University Belfast, Belfast, UK

2 Warwick Mathematics Institute, Coventry, UK

3 IMAPP, Radboud University Nijmegen, Nijmegen, The Netherlands 